\title{
Regulation of Fetal Growth Presidential Address, Society for Pediatric Research, May 1984
}

\author{
JOHN D. JOHNSON \\ Department of Pediatrics, University of New Mexico School of Medicine, Albuquerque, New Mexico 87131
}

It has been a pleasure and an honor to serve as President of the Society for Pediatric Research for the past year. During the past 7 years as an officer of the Society, I have witnessed a marked increase in the number of abstracts submitted and presented at the Annual Meeting. I have observed real vitality among officers and council members, with considerable commitment to furthering pediatric research, including the establishment 2 years ago of the Young Investigator Award, and now the Starter Research Grant Program. Thus, I am very optimistic about the future of the Society.

I recognize that many problems exist for the biomedical and pediatric research communities, including difficulties with stable or enhanced funding, with attracting young investigators into research careers in pediatrics and the diversion of faculty efforts toward the generation of income from clinical activities to the detriment of time spent on research. Yet, I have no novel proposals for solutions to these recognized problems; thus, I have chosen not to be philosophic and to devote the remainder of this address to a scientific subject.

The topic I have chosen to address is "Regulation of Fetal growth." This is a broad subject, so I will restrict my comments to selected areas which reflect my own interests and biases. The clinical relevance of this topic is great. It is estimated that $40 \%$ of low birth weight infants are intrauterine growth retarded rather than premature. The small decline in prevalence of low birth weight infants in the United States during the 1970s was due largely to a decrease in term, small for gestational age infants (1). This suggests that intrauterine growth-retardated infants represent the category of low birth weight infants most amenable to change, that which we could affect even more dramatically if we understood the pathogenesis more thoroughly.

I hope to raise several conceptual issues and questions regarding fetal growth for which we do not yet have complete answers, hoping to stimulate further research in this area. It should also be emphasized that there may be a commonality between growth and differentiation or function-that factors impairing fetal growth may also interfere with normal cell and organismal differentiation. First, let us consider the relationship of placental blood flow to fetal growth. There is a strong correlation among uteroplacental blood flow, placental size, and fetal size. In humans, placental weights are greatest in large for gestational age infants and lowest in small for gestional age infants (2). Saintonge and Rosso (3) observed a reduction in placental blood flow in spontaneously growth-retarded fetuses and increased flow in spontaneously macrosomic fetuses. Importantly, Myers et al. (4) studying this same phenomenon in chronically catheterized guinea pigs removed from the surgical stresses known to influence metabolism and cardiovascular function, found a similar relationship, viz, a strong correlation between placental blood flow and spontaneous fetal weight.

Supported in part by NIH Grants HD 15243 and HD 11327.
This correlation can be extended to the normal maternal hematologic and cardiovascular adaptations to pregnancy. As early as 1958, Cope et al. (5) demonstrated that the increase in maternal plasma volume during pregnancy correlated with weights of the placenta and the newborn infant. Longo (6) has pointed out positive correlations among maternal whole blood, plasma and erythrocyte volumes, and fetal weight in humans. Recent investigations in acutely catheterized pregnant rats have demonstrated that food restriction, which decreases fetal size, is associated with reduced placental blood flow, presumably secondary to decreased cardiac output concomitant with reduced plasma volume expansion (7). If this is true, one does not need to invoke reduced maternal blood concentration of nutrients to explain the growth retardation observed with caloric restriction.

Thus, there is considerable evidence supporting the view that the increase in blood volume accompanying normal pregnancy and the associated increase in uteroplacental blood flow represent the central regulatory factors influencing placental size, and, thereby, fetal size. However, most of this is correlative data and we are all aware of the dictum that correlation does not connote causality-at least not necessarily. It is possible that a primary disturbance of fetal growth or metabolism, e.g. some alteration in hormonal or growth factor production, also leads to reduced placental growth, and, secondarily, to diminished uteroplacental blood flow. Longo (6) has proposed mechanisms by which such an effect could be operative in humans. Pregnenolone, derived from the placenta, is converted to dehydroepiandrosterone sulfate in the fetal adrenal. Dehydroepiandrosterone sulfate is subsequently converted to estradiol- $17 \beta$ and estrone in the placenta. These compounds in turn stimulate the maternal renin-angiotensin-aldosterone system causing retention of extracellular fluid, thereby increasing maternal plasma volume. Chorionic somatomammotropin stimulates maternal erythropoiesis and increases red cell mass. The resulting augmentation of blood volume results in increased cardiac output, increased uteroplacental blood flow, and transfer of flow-dependent substrates such as amino acids to the fetus. In this interaction the fetus is far from a passive participant, but rather has some control of its own destiny. One can envision fetal factors other than adrenal steroid production that might be operative in the regulation of placental function. Studies to test these hypotheses should be undertaken.

A second issue of interest is the different patterns of fetal growth at different stages of gestation. The late phase of gestation is devoted largely to fetal energy storage, in the form of fat and carbohydrate, as well as to biochemical "fine-tuning" in preparation for extrauterine adaptation. Earlier in gestation cell proliferation and accretion of protein are the dominant features of fetal growth. This could mean that humoral regulation of fetal growth varies at different stages of gestation. The humoral regulation of growth in the fetus differs significantly from postnatal growth regulation. Jost (8) and other investigators have established that growth hormone is not an important regulator of fetal 
size. Similarly, in most species, thyroid hormone has little influence on fetal size. In contrast, there is considerable evidence implicating insulin as a significant fetal growth factor, at least during late gestation. The Pedersen (9) hypothesis states that macrosomia in infants of diabetic mothers is the result of fetal hyperinsulinemia. Conversely, the rare infant with pancreatic agenesis is markedly undergrown at birth. Both animal and human studies demonstrate an association between fetal weight at term and plasma insulin concentration. Results obtained by Girard et al. (10) in the rat show that near term body weight and plasma insulin correlated positively, while weight and plasma growth hormone concentration correlated negatively. Of course, such associations do not prove a causal role for insulin in fetal growth.

Therefore, various researchers have examined the effects of insulin administration on fetal growth. Picon (11) injected rat fetuses with large daily doses of insulin for 3 days late in gestation and found, relative to controls, increased weight, nitrogen content, and lipid content at term. Susa et al. (12) infused insulin continuously to rhesus monkey fetuses during the latter part of pregnancy and reported a $34 \%$ increase in body weight versus age-matched controls, with increased size of the heart, liver, spleen, and, most dramatically, the placenta. Although other studies employing different species have produced different results, there is now a considerable body of data sugesting an anabolic role for insulin in the fetus.

Thus, we might ask 1) How is insulin secretion regulated in the fetus? and 2) how might insulin act in modulating fetal metabolism and growth? Studies in the chronically catheterized fetal sheep indicate that plasma glucose and insulin concentrations correlate strongly (13). Glucose is maximally stimulatory to fetal insulin release at quite low concentrations, but the slope of the dose-response curve is identical in fetal and adult animals. Inhibition of insulin release by adrenergic mechanisms is well developed from early gestation in the fetal sheep (14). Since catecholamines play an important role in mediating the response of the fetus to hypoxia, catecholamine inhibition of insulin release may influence growth during chronic hypoxia. Thus, changes in glucose or oxygen supply across the placenta, modulating fetal insulin secretion, theoretically could allow the fetus to participate in regulating its own metabolic processes.

What are the metabolic actions of insulin in the fetus? In postnatal animals insulin is known to have diverse anabolic actions, including its well-known effects on glucose uptake and lipogenesis, but insulin also exerts effects on amino acid and protein metabolism, such as increased amino acid uptake, stimulation of protein synthesis in some tissues, and inhibition of protein degradation in many tissues. In the fetus we know much less about insulin's actions, but some data are available. For example, Simmons et al. (15) have demonstrated that insulin infusion into fetal sheep late in gestation results in increased umbilical uptake of glucose and increased fetal glucose utilization. However, these effects of insulin on carbohydrate metabolism, as well as those on lipid metabolism, occur only late in gestation.

Much less work has been conducted on other potential actions of insulin which might be important earlier in gestation, such as cellular proliferation and protein turnover. Insulin is known to promote DNA synthesis and cell proliferation in a number of tissue culture systems, including fibroblasts from chick, mouse, and rat embryos. Insulin stimulates amino acid uptake by chick embryo heart as early as 5 days, whereas glucose transport is not sensitive to insulin until 7-10 days of incubation (16). Sperling et al. (17) have presented evidence that amino acid uptake by isolated fetal rat hepatocytes is stimulated by insulin, while ${ }^{14} \mathrm{C}$ glucose incorporation into glycogen is not. This suggests separate insulin-mediated post receptor events which mature independently. It seems reasonable to postulate that the growth-promoting action of insulin in the fetus may be related to increased cell proliferation and protein accretion early in gestation, at least in some tissues, while late in gestation the major effects of insulin relate to energy storage. Further studies of insulin action in early and mid-gestation should help test this hypothesis.

Let us now probe the potential role for somatomedins and other growth factors in the regulation fetal growth and, as a corollary, whether combinations of growth factors acting in concert might promote optimal fetal growth. Although the evidence for such a role for somatomedins is indirect, it becomes progressively more compelling. Unlike specific growth factors, such as nerve growth factor, which have quite specialized target cell populations, somatomedins appear to influence the growth of many types of cells. Somatomedins stimulate mitosis of many fetal cell types in organ or tissue culture.

Moreover, numerous fetal tissues contain specific somatomedin binding or receptor sites. These include placenta, brain, monocytes, and other tissues. D'Ercole et al. (18) have shown that specific binding of somatomedin- $C$ to the fetal side of the pig placenta increases as gestation advances, suggesting another mechanism whereby fetal factors may influence placental and, indirectly, maternal metabolism. Rosenfeld et al. (19) have reported that specific binding of somatomedin- $C$ to circulating mononuclear cells in human cord blood is greater than to adult mononuclear cells. Thus, there may be increased sensitivity of fetal tissues to somatomedins.

Several fetal tissues have been shown to elaborate somatomedins. D'Ercole et al. (20) have studied somatomedin synthesis by explants of fetal mouse tissues. Somatomedin-C content in media from organ explants of the 17-day fetus increased considerably during 3 days in culture for all tissues assayed except placenta.

In humans, somatomedin concentrations in fetal blood correlate with size at birth $(18,21)$. The concentration of multiplication-stimulating activity, the rat homologue of IGF-II, is very high in fetal rat serum compared to postnatal concentrations (22). However, studies in humans reveal lower levels of both major somatomedin types (IGF-I and IGF-II) in fetal than in adult blood. This finding would not seem to support the proposed growth-promoting role for somatomedins in the human fetus, but several arguments can be adduced to explain this apparent incongruity. There is evidence, already alluded to, for increased sensitivity of tissues of the fetus to somatomedins. In addition, the fact that somatomedins are synthesized by numerous fetal tissues suggests the possibility that they are operating by paracrine or autocrine mechanisms rather than by classical endocrine mechanisms, i.e. that fetal tissues are elaborating somatomedins which act on nearby cells or, in fact, which promote their own growth. If this is true, serum concentrations of these agents are less relevant.

Parenthetically, Roth et al. (23) have recently found that peptide molecules previously considered to be purely endocrine, and originating in specialized unique cell types, such as insulin and $\mathrm{ACTH}$, are present in unicellular and primitive multicellular organisms. They propose that these intercellular communicators began evolutionally and embryologically as local tissue factors acting first as autocrine secretions, subsequently in a paracrine manner on neighboring cells; and, finally, with morphological and developmental advances, some of the messenger molecules developed into humoral agents. It is reasonable to presume that somatomedins in fetal life progress through this same sequence, from autocrine to paracrine to endocrine functions-another example of ontogeny recapitulating phylogeny.

There also may be a role in fetal growth for the numerous other polypeptide growth factors which have been identified, and there may be cooperative interactions among these factors. Kaplowitz et al. (24) have illustrated how some of these growth factors may interact with their studies of the growth of embryonic mouse limb bud mesenchyme. Several factors stimulate mitogenesis of limb bud cultures when studied individually, such as epidermal growth factor, fibroblast growth factor, insulin, multiplication-stimulating activity, and somatomedin-C. Yet, maximal growth requires the presence simultaneously of several factors: conditioned medium from liver explants, epidermal growth 
factor, fibroblast growth factor, and either insulin or somatomedin-C.

That multiple growth factors are required for optimal rates of cell division in such a system is not surprising in view of studies by Stiles et al. (25) on the effects of growth factors on regulation of the cell cycle. These investigators identified at least two control points in the cell cycle for specific growth factors. The growth cycle of exponentially multiplying cells is divided into four discrete phases: G1, the period between mitosis and DNA synthesis; S, the period of DNA synthesis; G2, the period between DNA synthesis and mitosis; and $M$, mitosis. When cell confluency is reached, replicative DNA synthesis and cell division are arrested. This quiescent phase is designated $\mathrm{G}_{0}$. Entry back into the $\mathrm{S}$ phase requires a combination of growth factors. One type of factor, represented by platelet-derived growth factor or fibroblast growth factor renders cells competent to enter $\mathrm{S}$. These factors in and of themselves will not allow cells to synthesize DNA. The second type of factor, known as a progression factor, allows competent cells to progress through $G_{0}$ and $G_{1}$ and enter the $\mathrm{S}$ phase. Somatomedins, as well as epidermal growth factor, are potent progression factors in selected cell types. For the Tlymphocyte, lectins such as concanavalin A serve as competence factors, while the T-cell specific growth factor, interleukin-2, serves as the progression factor. Thus, there may be coordinate control of cell growth by these types of growth factors.

Provocative recent work in the oncogene field prompts one to speculate not only on the mechanisms by which viral oncogenes promote tumorigenesis, but also on the regulation of normal cell growth. Evidence indicates that oncogenes may act to transform normal cells in different ways, e.g. by coding for the synthesis of growth factors such as platelet-derived growth factor, allowing independent proliferation via "autocrine" secretion $(26,27)$, or by causing expression of uncontrolled growth factor receptor function (28). It is not fatuous to speculate that the products of protooncogenes, the normal cellular counterparts of viral oncogenes, are important in the regulation of fetal growth. As cell biology and cancer biology rapidly meld, studies of the control of protooncogene expression may improve our understanding of the regulation of embryonc and fetal growth.

Finally, I wish to emphasize that the accretion of any substance during growth is the result of the net balance between its synthesis and degradation. Thus $\mathrm{Kg}=\mathrm{Ks}-\mathrm{Kd}$, where $\mathrm{Kg}$ represents the fractional growth rate for protein, Ks the fractional rate of synthesis, and $\mathrm{Kd}$ the fractional rate of degradation. Studies of protein turnover by Meier et al. (29) in the fetal sheep show that early in the 3rd trimester both $\mathrm{Ks}$ and $\mathrm{Kd}$ are high and both decrease as gestation proceeds. The high rates of degradation found in some growing tissues may be necessary for the remodeling which accompanies growth. Our own studies indicate, however, that different fetal tissues have different patterns of protein turnover than those seen in the whole organisms. In vivo determination of protein turnover in the fetal rat shows that Ks is higher and $\mathrm{Kd}$ lower in heart and diaphragm during the phase of most rapid growth (day 19) than during a phase of slower growth (day 21), at which time Ks falls and $\mathrm{Kd}$ increases (30). Interestingly, postnatal protein accretion in various tissues of the rat, such as skeletal muscle and liver, occurs by different mechanisms than those operative in fetal life.

Thus, growth in the fetus can be modified by either changes in rates of protein synthesis and/or rates of degradation. Studies of protein degradative mechanisms during fetal life should help our understanding of growth regulation. We now recognize two independent mechanisms for intracellular protein degradation: one cytoplasmic and energy dependent, involved primarily in breakdown of rapidly metabolized proteins; and two lysosomal in location, involved in degradation of proteins with long halflives. The lysosomal process is dependent on calcium ion concentration. Greenberg et al. (31) have shown that calcium does not stimulate proteolysis in fetal striated muscle, and that inhibitors of lysosomal enzymes such as EP 475 do not affect total proteolysis by fetal muscle. This l-.... r observation is not the result of a lack of lysosomal enzyme activity in fetal muscle. Presumably, some step in the process by which autophagic vacuoles fuse with lysosomes is deficient in fetal muscle, and this deserves further experimentation.

To summarize, a variety of maternal, placental, and intrinsic fetal factors are involved in the regulation of fetal growth. There are several recognized, and probably many unrecognized interactions among these components, and there are many unresolved cart versus horse issues in these interactions.

Some quesitons which need to be answered include the following.

1) Are there intrinsic placental factors that modify placental vascular resistance and thus influence placental blood flow, and what factors regulate maternal blood volume expansion?

2) How might fetal hormones and growth factors influence placental growth and/or function and thus affect nutrient delivery to the fetus? We are in need of better markers of placental growth and function to study this question. Weight, DNA, RNA, and protein content of this complex organ are not sufficient. Markers of endothelial surface area, such as factor VIII antigen or angiotensin-converting enzyme, may be more pertinent in future studies of placental growth.

3) What factors control the expression of genes for the fetal polypeptide growth factors?

4) What are the mechanisms of protein degradation in the fetus and how might fetal hormones or growth factors affect this process?

5) How can we better define the interactions of factors contributing to the regulation of fetal growth?

Although developmental physiologists, biochemists, molecular biologists, morphologists, and endocrinologists may each propose critical arbiters of fetal growth, the conceptual issues I have discussed suggest that, at present, there is no unifying simplistic regulator of fetal growth. I hope that the questions I have raised will be of heuristic value for further investigation.

Acknowledgment. The author is indebted to Robert Greenberg for valuable discussions while preparing this address.

\section{REFERENCES}

1. Kessel SS, Villar J, Berendes HW, Nugent RP 1984 The changing pattern of low birth weight in the United States. 1970 to 1980 . JAMA 251:1978-1982

2. Molteni RA, Stys SJ, Battaglia FC 1978 Relationship of fetal and placental weight in human beings: Fetal/placental weight ratios at various gestational ages and birth weight distributions. J Reprod Med 21:327-334

3. Saintonge J, Rosso P 1981 Placental blood flow and transfer of nutrient analogs in large, average and small guinea pig littermates. Pediatr Res 15:152-156

4. Myers SA, Sparks JW, Makowski EL. Meschia G, Battaglia FC 1982 Relationship between placental blood flow and placental and fetal size in guinea pig. Am J Physiol 243:H404-H409

5. Cope I, Pirani BBK. Campbell DM. MacGillirray I 1958 Plasma and blood volume changes in late and prolonged pregnancy. J Obstet Gynaecol $\mathrm{Br}$ Commonwealth 65:877-894

6. Longo LD 1984 Intrauterine growth retardation: a "mosaic" hypothesis of pathophysiology. Sem Perinatol 8:62-72

7. Rosso P and Kava R 1980 Effects of food restriction on cardiac output and blood flow to the uterus and placenta in the pregnant rat. J Nutr 110:23502354

8. Jost A 1954 Hormonal factors in the development of the fetus. Cold Spring Harbor Symp Quant Biol 19:167-181

9. Pederson J 1977 Hyperglycemia-hyperinsulinism therapy and birth weight. In: The Pregnant Diabetic and Her Newborn. Problems and Management, 2nd ed. Williams \& Wilkins, Baltimore, pp 211-220

10. Girard JR, Rieutort M, Kerrvran A, Jost A 1976 In: Rooth G and Bratteby LE (eds) Perinatal Medicine. Almqvist and Wiskell, Stockholm, pp 197-202

11. Picon L 1967 Effect of insulin on growth and biochemical composition of the rat fetus. Endocrinology 81:1419-1421

12. Susa JB, McCormick KL. Widness JA, Singer DB. Oh WH, Adamsons K. Schwartz R 1979 Chronic hyperinsulinemia in the fetal rhesus monkey: effects on fetal growth and composition. Diabetes 28:1058-1063

13. Phillips AF. Carson BS. Meschia G. Battaglia FC 1978 Insulin secretion in fetal and newborn sheep. Am J Physiol 235:E467-E474

14. Bassett JM 1977 Glucagon, insulin and glucose homeostasis in the fetal lamb. Ann Rech Vet 8:362-373

15. Simmons MA. Jones MD. Battaglia FC. Meschia G 1978 Insulin effect on fetal glucose utilization. Pediatr Res 12:90-92 
16. Guidotti G, Foa PP 196I Development of an insulin-sensitive glucose transport system in chick embryo hearts. Am J Physiol 201:869-872

17. Sinha MD. Miller JD Ganguli S. Sperling MA 1983 Differential maturation of insulin sensitivity for glucose and amino acid metabolism in rat hepatocytes. Pediatr Res 17:142A(abstr)

18. D'Ercole AJ, Foushee DB. Underwood LE 1976 Somatomedin-C recepto ontogeny and level in porcine fetal and human cord serum. $J$ Clin Endocrino Metab 43:1069-1077

19. Rosenfeld R. Thorsson AV, Hintz RL 1979 Increased somatomedin receptor sites in newborn circulating mononuclear cells. J Clin Endocrinol Metab 48:456-461

20. D'Ercole AJ. Applewhite GT. Underwood LE 1980 Evidence that somatomedin is synthesized by multiple tissues in the fetus. Dev Biol 75:315-328

21. Foley TP. DePhilip R. Perricelli A. Miller A 1980 Low somatomedin activity in cord serum from infants with intrauterine growth retardation. J Pediatr 96:605-610

22. Moses AC, Nissley SP. Short PA. Rechler MM. White RM, Knight AB, Higa OZ 1980 Increased levels of multiplication stimulating activity, an insulinlike growth factor. in fetal rat serum. Proc Natl Acad Sci USA 77:3649-3653

23. Roth J, LeRoith D Shiloach J, Rosenzweig JL Lesniak MA, Havrankova J 1982 The evolutionary origins of hormones, neurotransmitters. and other extracellular chemical messengers. N Engl J Med 306:523-527

24. Kaplowitz PB, D’Ercole AJ. Underwood LE 1982 Stimulation of embryonic mouse limb bud mesenchymal cell growth by peptide growth factors. $\boldsymbol{J}$ Cell Physiol 112:353-359

25. Stiles CD, Capone GT, Scher CD, Antoniades HN, Van Wyk JJ, Pledger WJ 1979 Dual control of cell growth by somatomedins and platelet-derived growth factor. Proc Natl Acad Sci USA 76:1279-1283

26. Doolittle RF, Hunkapillar MW, Hood LE, Devare SG, Robbins KC, Aaronson SA, Antoniades HN 1983 Simian sarcoma virus onc gene, v-sis, is derived from the gene (or genes) encoding a platelet-derived growth factor. Science 221:275-277

27. Waterfield MD, Scrace GT, Whittle N, Stroobant P, Johnsson A, Wasteson A Westermark B, Heldin CH. Huang JS. Deuel TF 1983 Platelet-derived growth factor is structurally related to the putative transforming protein $\mathrm{p}$ 28 sis of simian sarcoma virus. Nature 304:35-39

28. Downward J, Yarden Y. Mayes E, Scrace G, Totty N, Stockwell P, Ullrich A Schlessinger J, Waterfield MD 1984 Close similarly of epidermal growth factor receptor and v-erb-B oncogene protein sequences. Nature 307:521527

29. Meier PR, Peterson RG, Bonds DR, Meschia G, Battaglia FC 1981 Rates of protein synthesis and turnover in fetal life. Am J Physiol 240.E320-E324

30. Johnson JD, Wetmore DL 1984 Protein turnover in heart and diaphragm of the rat fetus. Am J Physiol 247:E781-E785

31. Greenberg RE, Davis A, Wogenrich J, Barela TD 1983 Development of proteolytic mechanisms. Pediatr Res 17:133A(abstr) 